\title{
Dynamic Pricing of Fashion-Like Multiproducts with Customers' Reference Effect and Limited Memory
}

\author{
Mengqi Liu, ${ }^{1}$ Wenjie $\mathrm{Bi}^{2}{ }^{2}$ Xiaohong Chen, ${ }^{2}$ and ${\mathrm{Guo} \mathrm{Li}^{3}}^{3}$ \\ ${ }^{1}$ Business School, Hunan University, Changsha 410082, China \\ ${ }^{2}$ Business School, Central South University, Changsha 410083, China \\ ${ }^{3}$ School of Management and Economics, Beijing Institute of Technology, Beijing 100081, China \\ Correspondence should be addressed to Wenjie Bi; wenjie-bi@hotmail.com
}

Received 28 November 2013; Accepted 27 January 2014; Published 13 March 2014

Academic Editor: Xiaohang Yue

Copyright (C) 2014 Mengqi Liu et al. This is an open access article distributed under the Creative Commons Attribution License, which permits unrestricted use, distribution, and reproduction in any medium, provided the original work is properly cited.

\begin{abstract}
We study a fashion retailer's dynamic pricing problem in which consumers present reference effect and memory window. Based on the theory of Baucells et al. (2011), we propose a new reference-price updating mechanism in fashion and textile (FT) industry where consumers have a bounded memory window and anchor on the first and most recent price in any memory window. Moreover, we study the impacts of this mechanism on optimal pricing policy for a retailer selling multiple fashion-like products and analyze optimal price's steady state, monotonicity, and convergence. For two-product case, we find that, for otherwise identical products, the steady-state price of a core product is lower than that of a noncore product. We compute the retailer's loss of revenue if he incorrectly assumes the reference-price effect to be at the product level and prices the products individually. Further, as illustrated with numerical results, our model is a flexible way to make pricing strategy if the retailer can anticipate the length of consumers' memory window.
\end{abstract}

\section{Introduction}

The fashion and textiles (FT) industry is a major economic sector in developing countries such as China and it has made significant contributions to economic growth and employment in these areas over the past decade. In recent years, dynamic pricing has aroused widespread attention in all walks of life. However, when applied to the sales of fashionlike goods, sellers need to account for key characteristics of the sales environment, including the scarcity of goods, demand uncertainty, and consumer behavior (Aviv and Pazgal [1]). The frequent change of consumers' preference is the main reason why the demand of FT industry shows more variations and its product has a shorter life circle than that in other industries. Therefore, sellers should change the products' price dynamically to lure more consumers and be sensitive to their behavior. For example, markdowns and sales have long been ubiquitous in FT industry. Another example is that Zara, a large Spanish producer and retailer of fashion goods, limits the number of clothing items in each store in order to create a sense of urgency among consumers (Ghemawat et al. [2]). Some consumers are afraid of stockout and thus Zara earns more profits than providing an ample supply. Empirical studies show that customers' purchase decisions are influenced by reference price to a large extent. In the case of retailer selling multiple fashion products or other seasonal products called fashion-like products, consumers' reference price of a store may be shaped by a small number of products called core products; retailer can attract more consumers through lowering the price of core products, thus promoting sales of noncore products and earning more profits.

We consider that a retailer sells multiple fashion-like products over a series of selling periods in a repeated purchase market, where consumers format their price expectations according to past price they can remember. Two problems which the retailer is facing are (1) how to incorporate consumers' reference-price updating mechanism into its revenue management decisions and (2) how to price its multiple 
fashion-like products to optimize its long-term profit and in the meantime attract more consumers.

The contributions of this paper include the following. (1) Unlike exponential smoothing model in the previous literature, we offer a new, behaviorally motivated anchoring mechanism based on Baucells et al. [3] and bounded memory decision theory (Sarin [4]). We call it first-end anchoring in which consumers have a memory window and anchor on the first and most recent price in any memory window $\tau$. (2) We introduce our new reference-price updating model into the optimal pricing policy for a retailer selling multiple fashionlike products and analyze its steady state, monotonicity, and convergence. We find that, for otherwise identical products, the steady-state price of a core product is lower than that of a noncore product. We compute the retailer's loss of revenue if he incorrectly assumes the reference-price effect to be at the product level and prices the products individually.

The remainder of the paper is organized as follows. Section 2 reviews related literature. Section 3 develops general models of demand and reference-price formation based on behavioral assumptions and sets up the multiproduct dynamic pricing problem of a fashion-like products retailer. Section 3 also characterizes the steady state and convergence of optimal price strategy for two and $N$ products. Section 4 analyzes the imparity of store-level pricing and product-level pricing and conclusions are provided in Section 5.

\section{Literature Review}

Recently, dynamic pricing and revenue management have gained an increasing popularity in retail settings and engendered a growing body of academic research in recent years (for a recent survey, see Bitran and Mondschein [5]). Lazear [6] and Aviv and Pazgal [1] discuss dynamic pricing of fashion goods, where some characteristics of the demand are unknown. In these papers, prices serve both as a tool for revenue generation and as a learning mechanism. Aviv et al. [7] think that retailers of products with short life cycle such as fashion products face a significant level of uncertainty about demand, so it is necessary to improve their pricing as the retailer observes the sales of the their product. Zhao and Zheng [8] consider a dynamic pricing model for selling a given stock of a perishable product over a finite time and also show that using optimal dynamic optimal policies can largely improve the revenue. Similarly, Bhattacharjee and Ramesh [9] consider a multiperiod inventory and pricing model for a single product at the retail end of the supply and show that the maximum profit function is continuous piecewise concave. Further, Bitran and Mondschein [10] study intertemporal pricing policies when selling seasonal products in retail stores and show that the structure of the optimal pricing policies is consistent with the procedures observed in practice. At the same time, the topic of behavioral operation has drawn academician's attention in both academic research and industry practice. Loch [11], Gino, and Pisano [12] provide an overview and also recommend potential research topics. These review papers suggest that psychological factors and behavioral regularities may have important implications on operational problems.
A recent review on modeling customer behavior in revenue management and auctions is by Shen and $\mathrm{Su}$ [13]. Other related works in behavioral operations that incorporate consumer learning models include Gaur and Park [14], Liu and van Ryzin [15], and Ovchinnikov and Milner [16]. Natter et al. [17] describe a decision-support system for dynamic retail pricing and promotion planning. And their demand model incorporates price, reference-price effects, seasonality, article availability information, features, and discounts.

There is a vast amount of literature on how retailers should optimally their prices when consumers anchor on reference prices (Fibich et al. [18], Heidhues and Koszegi [19], Popescu and $\mathrm{Wu}$ [20], Huh et al. [21], and Arslan and Kachani [22]). Greenleaf [23] analyzes the impact of reference-price effect on a single-period promotion. Puller and West [24] investigate whether the retail prices of electricity and natural gas send proper signals about scarcity in order to induce efficient consumption and also consider the reference price. In behavioral economics field (see Ho et al. [25]), they propose a new model, where the reference price is defined as internal, rational expectations equilibrium. Yucek and Arslan [26] consider a retailer's decision on the product introduction timing and dynamic pricing for successive product generations in the presence of reference-price effects. Also under a discrete-time framework, Kopalle et al. [27] use dynamic programming to study the optimal pricing policy under asymmetric reference-price effect. They further discussed a setting where brands compete in an oligopoly. In a continuous-time framework, Fibich et al. [18] study the dynamic pricing problem under both symmetric and asymmetric demand function. Their work provides an elegant explicit solution to the optimal price process using optimal control. Popescu and $\mathrm{Wu}$ [20] extend these findings to general demand functions and reference effects and provide structural results. Like previous studies, they show that loss aversion leads to a range of steady states, which collapses to a single point for loss neutral buyers. Huh et al. [28] extend the model in Kopalle et al. [27] to a setting in which consumers are offered two separate prices. They classify consumers into two classes depending on how they form their reference prices: price-takers and price-hagglers. Price-takers form their reference prices through exponential smoothing reference-price process. Nasiry and Popescu [29] study the impacts of a new memory-based reference-price formation, based on a peak-end memory model of Fredrickson and Kahneman [30], on dynamic pricing policies with referenceprice effects. This new memory-based reference-price model suggests that consumers develop a reference price based on a weighted average of the lowest and the most recent prices.

A common assumption in literature mentioned above is that consumers' reference price is a weighted average of past prices. Specifically, the reference-price updating mechanism follows an exponentially smoothed adaptive expectations process (Mazumdar, et al. [31]). These models are built on behavioral theories (prospect theory, mental accounting, etc.) but pay little attention to the anchoring and memory processes, that is, how reference prices are formed. Recently, Baucells et al. [3] show that reference points are not recursive, in the sense that the new reference point is not a combination 
of the previous reference point and the new information. They analyze the data from the experiment and conclude that the first price and last price in a given window of time have the most influence on consumers' purchase decision (firstend anchoring), while the highest and lowest price received minor or no influence, a finding incompatible with exponential smoothing model and peak-end rule (Fredrickson and Kahneman [30, 32] and Do et al. [33]). Meanwhile, some researches on repeated game and procedural choice show that an agent does not recall all past actions or payoffs but has a finite number of memory states. He can consider his actions only on the memory state he is currently in and he can update his memory state depending on the payoff received (Aumann and Sorin [34] and Sarin [4]).

As to multiproduct dynamic pricing, Gallego and van Ryzin [35] study a continuous-time model for yield management. Maglaras and Meissner [36] consider a multiproduct revenue management problem with multidimensional demand functions that map prices into demand rates. Asvanunt and Kachani [37] study the dynamic pricing with reference effects problem in discrete time which achieve similar results with the continuous model and they also extend their research to multiple products in duopoly markets. Our study on multiproduct's reference price is inspired by Calicchio and Krell's [38] research about the retailers' price promotion in Latin America. They argued that consumer's perception of a store's price level was largely shaped by a surprisingly small number of items (in our paper is called core products and these items are generally generic household items, such as socks and underwear). Therefore, pricing strategy of core products has profound implications on retailer's profit. A retailer may be able to attract more consumers and extract more profits by setting lower prices for core products and high noncore products, respectively. Based on this, we suppose that there are two kinds of formation mechanism of consumer's reference price. The first one is that consumer's reference price is only determined by the product itself called product-level reference price; another one is that consumer remembers prices of some core products in the store and then forms a reference price, which is called storelevel reference price. In this paper, we focus mostly on the latter.

\section{Model and Preliminary Results}

We consider that a retailer sells multiple fashion-like products over a series of selling periods in a repeated purchase market, where consumers format their price expectations according to past price they can remember. We describe how consumers make purchase decision based on prices and reference price and also how this decision affects the demand and profit. The notations that are used through the paper are listed in the Notations Section.

We consider an infinite horizon, multiproduct, determined, and periodic review model under a monopolistic setting. Demand in consecutive periods is independent and depends on the item's price and the consumers' reference price, which is based on the pricing history.
Assumption 1. As in Kopalle et al. [27] and Asvanunt and Kachani [37], we suppose that the demand function of product $j$ in the presence of reference-price effects is linear demand as follows:

$$
\begin{aligned}
D_{j}(p, r)= & a_{j}-b_{j} p_{j}+c_{G} \lambda_{j} \max \left\{r-\lambda_{\mathbf{p}, 0\}}^{\prime}\right. \\
& +c_{L} \lambda_{j} \min \left\{r-\lambda^{\prime} \mathbf{p}, 0\right\}, \quad j=1, . . N,
\end{aligned}
$$

where $a_{j}, b_{j}$, and $c$ are positive and $\lambda$ is a vector of nonnegative weights such that $\mathbf{1}^{\prime} \boldsymbol{\lambda}=1$. In other words, $\lambda^{\prime} \mathbf{p}$ is the weighted average price of the retail's products and is interpreted as the current store's price level. We see that the base demand is nonnegative, bounded, continuously differentiable, and decreasing in price.

In (1), if $c_{G}=c_{L}$, then consumers are loss neutral and the demand function is smooth. If $c_{G}<c_{L}$, then consumers are loss averse, the demand function is steeper for losses than for gains, and consumers respond more to surcharges than to discounts. This behavior is predicted by prospect theory: if $c_{G}>c_{L}$, then consumers are loss-seeking.

Moreover, we assume that the reference effect on each product is to be at the store level. Namely, the overall increase in demand of the entire store is $c_{G} \lambda_{j} \max \left\{r-\lambda^{\prime} \mathbf{p}\right.$, $0\}+c_{L} \lambda_{j} \min \left\{r-\lambda^{\prime} \mathbf{p}, 0\right\}$ and is allocated to each product proportionally according to $\lambda$.

The reference price $r_{t}$ is given by some updating mechanisms based on past prices. There are several models describing how the reference price is to be formed. The model proposed by Krishnamurthi et al. [39] regards reference price as the one period lagged price for a brand, mathematically denoted as $r_{t}=p_{t-1}$. Winer [40] proposes another reference-price model which sums past prices and observed price. Exponential smoothing is the most commonly used and empirically validated reference-price mechanism in the literature.

We introduce a new memory-based reference-price model, inspired by information weighting function proposed by Baucells et al. [3] and bounded memory decision theory (Bitran and Mondschein [10]). Based on empirical research and regression analysis, this function shows that if reference price is a weighted average of past price, then more than $80 \%$ weight should be given to the first (purchase price) and the last price in a time series, which means that consumers format and update their current reference price merely dependent on those two prices (i.e., first-end rule).

Assumption 2. Let $\mathbf{p}^{t}$ denote the observed selling price vector and customers' memory window is $\tau$ and let $\mathbf{p}^{t-\tau}$ denote the first price vector in the consumers' current memory window; then a reference- price updating mechanism is given by

$$
r^{t+1}=g\left(\mathbf{p}^{t-\tau}, \ldots, \mathbf{p}^{t-1}, \mathbf{p}^{t}\right)=\alpha \boldsymbol{\lambda}^{\prime} \mathbf{p}^{t-\tau+1}+(1-\alpha) \lambda^{\prime} \mathbf{p}^{t},
$$

where $0 \leq \alpha<1$ denotes the memory parameter and captures how strongly the reference price depends on the first price 
in the past $\tau$ periods. We refer to $\tau \geq 1$ as the length of consumers' memory window. When $\tau=1$, reference price equates recent price; that is, $r^{t}=\lambda^{\prime} \mathbf{p}^{t-1}$ which is a special case of Ghemawat et al. [2] by setting $\theta=0$. When $\tau=\infty$, which means that customers will remember the first price indefinitely, in most situations, $1 \leq \tau<\infty<\infty$; that is, consumers have finite memory window and will forget and update the initial price they remembered.

So the optimal dynamic pricing policy for the retailer is the solution to the following optimization problem:

$$
\begin{aligned}
\max \quad \sum_{t=0}^{\infty} \gamma^{t} D\left(\mathbf{p}^{t}, r^{t}\right)^{\prime} \mathbf{p}^{t} \\
\text { s.t. } \quad r^{t+1}=g\left(\mathbf{p}^{t-\tau}, \ldots, \mathbf{p}^{t-1}, \mathbf{p}^{t}\right) \\
=\alpha \lambda^{\prime} \mathbf{p}^{t-\tau+1}+(1-\alpha) \lambda^{\prime} \mathbf{p}^{t} .
\end{aligned}
$$

In the following analysis on two and $N$ products, we will only discuss the situation of $r^{0}>p_{G}^{*}$ for simplicity, which means that we only focus on $D_{j}(p, r)=a_{j}-b_{j} p_{j}+c_{G} \lambda_{j}(r-$ $\left.\lambda^{\prime} \mathbf{p}\right)$. And the situation of $r_{0}<p_{L}^{*}$ can be dealt with using the same method.

3.1. Two Products. In the two-product case, the demand of each product $j$ is given by

$$
\begin{array}{r}
D_{j}(p, r)=a_{j}-b_{j} p_{j}+c_{G} \lambda_{j}\left(r-\lambda^{\prime} \mathbf{p}\right) \\
\text { for } j=1,2 .
\end{array}
$$

The transition of the reference price is given by

$$
r^{t}=\alpha\left(\lambda_{1} p_{1}^{t-\tau}+\lambda_{2} p_{2}^{t-\tau}\right)+(1-\alpha)\left(\lambda_{1} p_{1}^{t-1}+\lambda_{2} p_{2}^{t-1}\right) .
$$

The retailer chooses a pricing policy that maximizes the total revenue from the two products. Hence, the Bellman equation we need to solve for the optimal policy is given by

$$
\begin{gathered}
V^{*}(r)=\max _{p_{1}, p_{2}} D_{1}\left(p_{1}, p_{2}, r\right) p_{1}+D_{2}\left(p_{1}, p_{2}, r\right) p_{2} \\
+\gamma V^{*}\left(g\left(p_{1}, p_{2}, r\right)\right), \\
r^{t}=\alpha\left(\lambda_{1} p_{1}^{t-\tau}+\lambda_{2} p_{2}^{t-\tau}\right)+(1-\alpha)\left(\lambda_{1} p_{1}^{t-1}+\lambda_{2} p_{2}^{t-1}\right) .
\end{gathered}
$$

Proposition 3. The steady-state prices for model (6), that is, for product 1 and product 2, equal $p_{1}^{L^{*}}, p_{2}^{L^{*}}$, where $p_{1}^{L^{*}}, p_{2}^{L^{*}}$ solve the following equations:

$$
\begin{aligned}
& k_{11} p_{1}^{L^{*}}+k_{12} p_{2}^{L^{*}}=a_{1}, \\
& k_{21} p_{1}^{L^{*}}+k_{22} p_{2}^{L^{*}}=a_{2} .
\end{aligned}
$$

And we get

$$
p_{1}^{L^{*}}=\frac{a_{1} k_{22}-a_{2} k_{12}}{k_{11} k_{22}-k_{12} k_{21}}, \quad p_{2}^{L^{*}}=\frac{a_{2} k_{11}-a_{1} k_{21}}{k_{11} k_{12}-k_{12} k_{21}},
$$

where

$$
\begin{aligned}
& k_{11}=\left(-2 b_{1}+c^{G} \lambda_{1}^{2}\left(\gamma\left(1-\alpha\left(1-\gamma^{\tau-1}\right)\right)-1\right)\right), \\
& k_{12}=k_{21}=\left(c^{G} \lambda_{1} \lambda_{2}\left(\gamma\left(1-\alpha\left(1-\gamma^{\tau-1}\right)\right)-1\right)\right), \\
& k_{22}=\left(-2 b_{2}+c^{G} \lambda_{2}^{2}\left(\gamma\left(1-\alpha\left(1-\gamma^{\tau-1}\right)\right)-1\right)\right) .
\end{aligned}
$$

For proof, see the appendix.

From Proposition 3, we can see that if $\lambda_{1}=\lambda_{2}=0.5$, then $p_{1}^{L^{*}}=p_{2}^{L^{*}}$ and the steady-state price is symmetric. Moreover, if $\lambda_{1}=1$ or $\lambda_{2}=1$, that is, if only one of the products influences the store's price level, the optimal pricing policy of two products is the same as that of a single product. If $\lambda_{1}>\lambda_{2}$, then $p_{1}^{L^{*}}<p_{2}^{L^{*}}$ which means that the retailer should set lower price for core products and set higher price for noncore products.

Proposition 4 shows that the optimal paths of two products have the same convergence properties as in single product.

Proposition 4. Given an initial reference-price $p^{-\tau+1}=$ $p^{-\tau+2}=\cdots=p^{-1}=p^{0}=r^{0}$, the optimal reference price $\left\{r^{*}\right\}$ and optimal price path $\left\{p_{1}^{L^{*}}, p_{2}^{L^{*}}\right\}$ converge monotonically to their respective steady state.

Proof. From (6), we know that profit function $\Pi\left(p_{1}, p_{2}, r\right)$ is submodular in $p_{1}, p_{2},-r$ for $\partial^{2} \Pi\left(p_{1}, p_{2}, r\right) / \partial p_{1} \partial(-r) \leq 0$, $\partial^{2} \Pi\left(p_{1}, p_{2}, r\right) / \partial p_{2} \partial(-r) \leq 0$, and $\partial^{2} \Pi\left(p_{1}, p_{2}, r\right) / \partial p_{1} \partial p_{2} \leq$ 0 . And according to Proposition 5 of Smith and Mccardle [41] value function $V(s)=\max (\Pi(p, s)+\gamma V(g(s, p)))$ is submodular in $p_{1}, p_{2},-r$ which means that $p_{1}, p_{2}$ are both monotonically increasing in $r$. On the other hand, $p$ and $r$ are bounded in $[p, \bar{p}]$. So the optimal price path $\left\{p^{*}\right\}$ converges monotonically to the steady state $\left[p_{1}^{L^{*}}, p_{2}^{L^{*}}\right]$.

3.2. Extension to the N-Products Case. The method of obtaining steady state of optimal pricing policy described in Proposition can be easily extended for an arbitrary number of products $N$. The steady state of optimal prices is the solution to a system of $N$ simultaneous equations, instead of the two given in (7).

Proposition 5. In the N-products case, the steady-state price for product $\mathrm{j}$ is solved:

$$
\left(\begin{array}{ccc}
k_{11} & \ldots & k_{1 n} \\
\vdots & \ddots & \vdots \\
k_{n 1} & \cdots & k_{n n}
\end{array}\right)\left(\begin{array}{c}
p_{1}^{t} \\
\vdots \\
p_{n}^{t}
\end{array}\right)=\left(\begin{array}{c}
a_{1} \\
\vdots \\
a_{n}
\end{array}\right),
$$




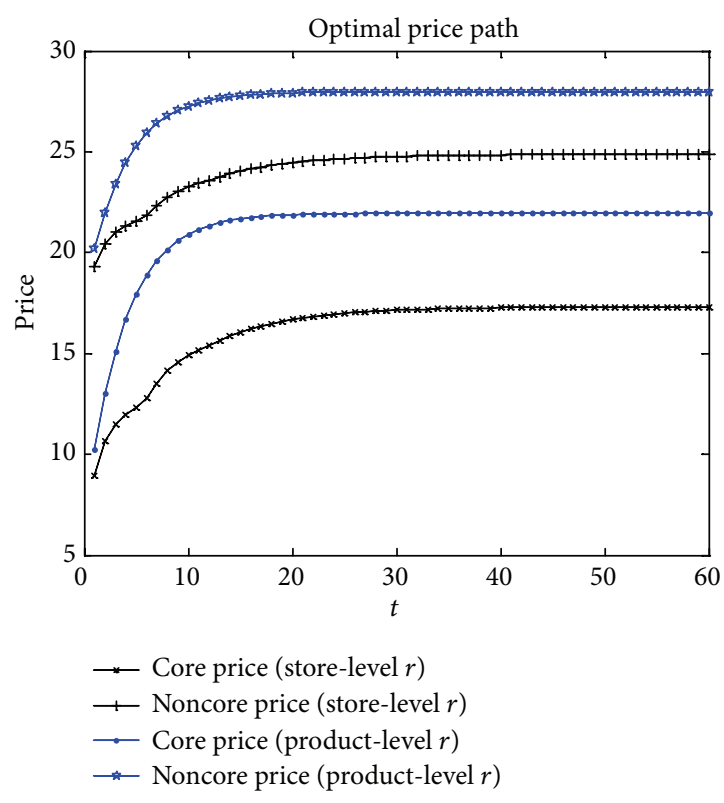

(a)

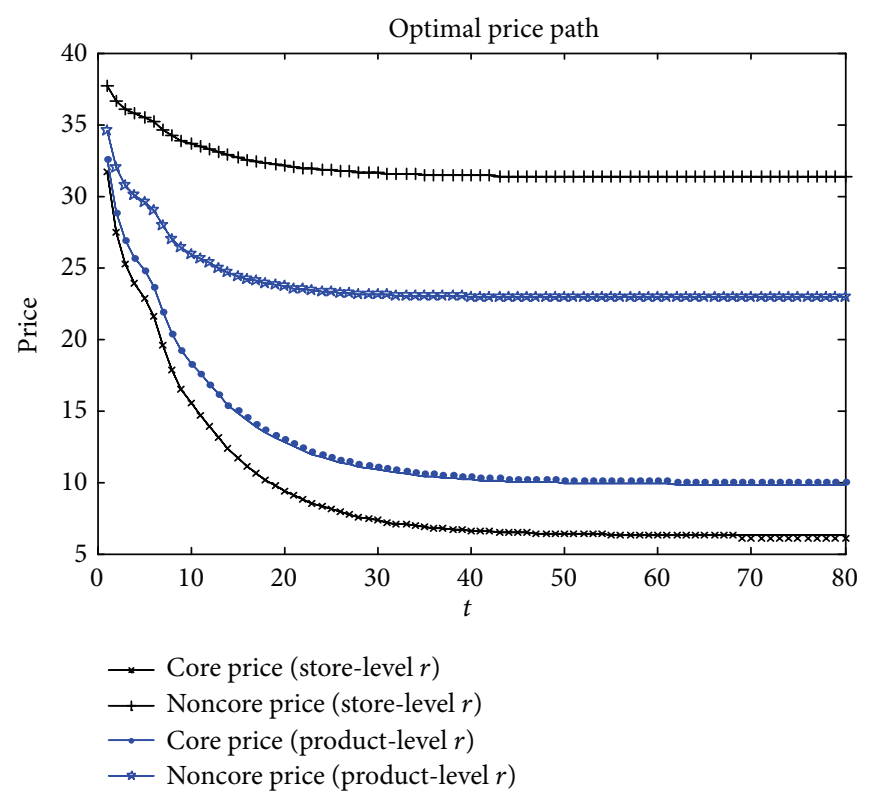

(b)

FIGURE 1: Optimal price path for store-level reference price and product-level reference price $\left(D_{1}\left(p_{1}, p_{2}, r\right)=40-0.5 p_{1}+20 * \lambda_{1}\left(r-\lambda_{1} p_{1}-\right.\right.$ $\left.\left.\lambda_{2} p_{2}\right), D_{2}\left(p_{1}, p_{2}, r\right)=40-0.5 p_{2}+20 * \lambda_{2}\left(r-\lambda_{1} p_{1}-\lambda_{2} p_{2}\right), r_{0}=10, \alpha=0.2, \gamma=0.95\right)$.

where

$$
\begin{gathered}
k_{i i}=-2 b_{i}+c^{G} \lambda_{i}^{2}\left(\gamma\left(1-\alpha\left(1-\gamma^{\tau-1}\right)\right)-1\right), \\
k_{i j}=c^{G} \lambda_{i} \lambda_{j}\left(\gamma\left(1-\alpha\left(1-\gamma^{\tau-1}\right)\right)-1\right), \quad i \neq j .
\end{gathered}
$$

And we get

$$
p_{j}^{L^{*}}=\operatorname{det} \frac{\left[\begin{array}{ccccc}
k_{11} & \cdots & k_{1 \cdot j-1}, a_{1}, k_{1 \cdot j+1} & \cdots & k_{1 n} \\
\vdots & \ddots & \vdots & & \ddots \\
k_{n 1} & \cdots & k_{n \cdot j-1}, a_{n}, k_{n \cdot j+1} & \cdots & k_{n n}
\end{array}\right]}{\operatorname{det}\left(\left[\begin{array}{ccc}
k_{11} & \cdots & k_{1 n} \\
\vdots & \ddots & \vdots \\
k_{n 1} & \cdots & k_{n n}
\end{array}\right]\right)} .
$$

Proof. This is similar to the proof of Proposition 3.

\section{Comparison between Store-Level and Product-Level Pricing}

In this section, we analyze the difference in revenue when a retailer selling fashion-like products chooses store-level pricing and product-level (Asvanunt and Kachani [37]) pricing, respectively. To facilitate comparison, we focus on twoproduct case and assume that both the initial price and the total demand for each product are the same.
There are two pricing policies the retailer can choose. The first one, called product-level pricing, is that retailer assumes that the reference price is based on the product level and the optimal policy is to follow the pricing policy of the singleproduct case given in following model:

$$
\begin{array}{r}
V_{j}(s)=\max _{p_{j} \in[\underline{p}, \bar{p}]}\left\{\prod_{j}\left(p_{j}, r_{j}\right)+\gamma\left(V\left(g\left(s, p_{j}\right)\right)\right)\right\} \\
\text { for } j=1,2, \\
r^{t}=\alpha p^{t-\tau}+(1-\alpha) p^{t-1}, \quad t \geq 1, \tau \geq 1,
\end{array}
$$

where $\prod_{j}(p, r)=\left(a_{j}-b_{j} p_{j}+c_{G} \lambda_{j}\left(r_{j}-p_{j}\right)\right) p_{j}$.

The second one, called store-level pricing, is that retailer assumes that consumers form their reference price on whole store's products and the optimal policy is to follow the pricing policy of the two-product case given in model (6).

Figure 1 shows the optimal price path of both products and the reference price over time for $r^{0}>p_{G}^{*}$ Figure 1(a) and $r_{0}<p_{L}^{*}$ Figure 1(b), respectively. In both cases, our study indicates that the retailer will set a lower price for the core products than some noncore products when he prefers to choose the store-level reference-pricing policy. The reason why he is willing to abandon the potential profits from the core product is that he wants to lure more consumers to visit his stores, thus accelerating the purchase of noncore products which have less reference effects in price than the core products. 


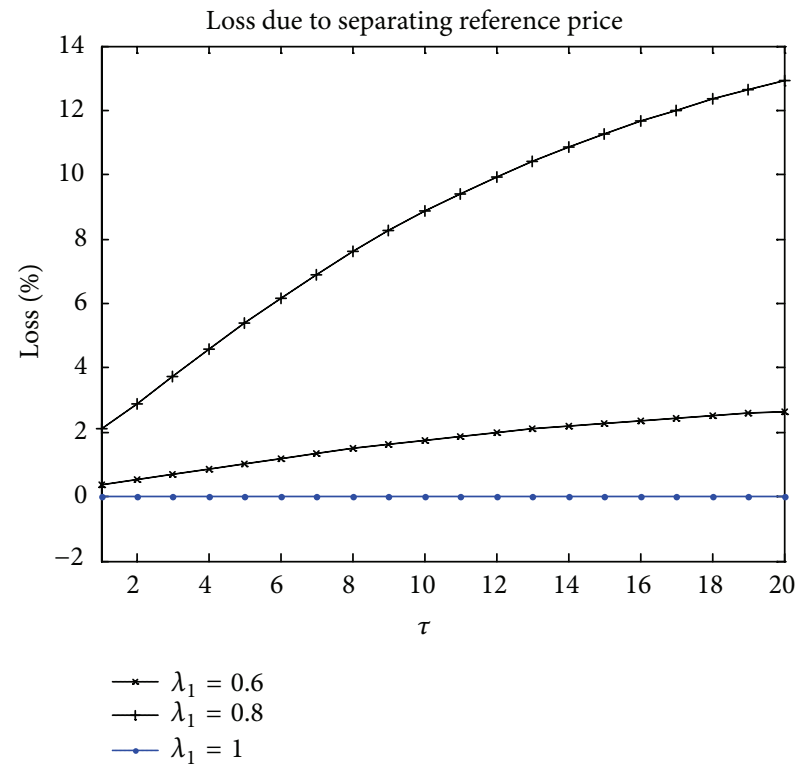

(a)

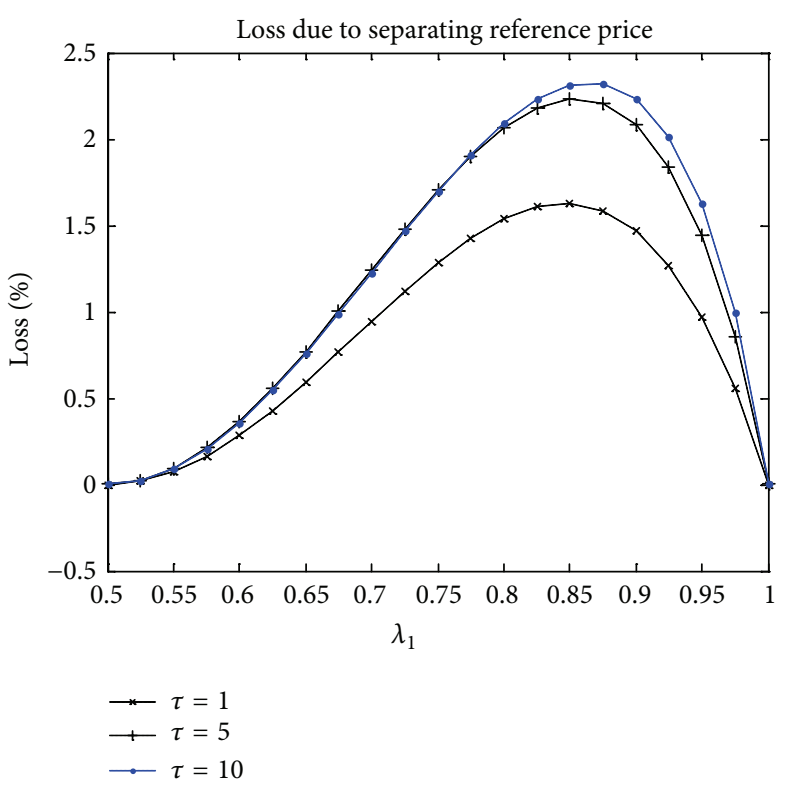

(b)

FIgURE 2: Effects of consumers' memory window on revenue loss for identical products $\left(D_{1}\left(p_{1}, p_{2}, r\right)=40-0.5 p_{1}+20 * \lambda_{1}\left(r-\lambda_{1} p_{1}-\right.\right.$ $\left.\left.\lambda_{2} p_{2}\right), D_{2}\left(p_{1}, p_{2}, r\right)=40-0.5 p_{2}+20 * \lambda_{2}\left(r-\lambda_{1} p_{1}-\lambda_{2} p_{2}\right), r_{0}=10, \alpha=0.2, \gamma=0.95\right)$.

Now, we would like to discuss the sensitivity of the influence factor $\lambda_{j}$, coupled with demand parameters $a_{j}, b_{j}$, and $c$. To begin with, we consider the revenue discrepancy when the demand functions of two products have identical parameters apart from the weights $\lambda_{j}$.

Figure 2 shows the revenue difference as a function of customers' memory windows $\tau$ and $\lambda_{j}$. Figure 2(a) shows that the revenue difference is increasing in $\tau$ when $0.5<\lambda_{1}<1$. Figure 2(b) shows that the difference is zero when $\lambda_{j}=0.5$ or 1 as analyzed in Section 4 . Furthermore, the results are symmetric when $\lambda_{j}=0.5$. Consequently, we only fix attention on the values of $\lambda_{j}$ between 0.5 and 1.

Figures 3(a), 3(b), and 3(c) illustrate the effect of magnitude of demand $a$, the demand price sensitivity $b$, and magnitude of reference-price effects $c$ on the loss of revenue. The common trend is that the loss of revenue is initially increasing in $\lambda_{1}$ and then becomes decreasing in $\lambda_{1}$ as it approaches 1 , for all values of $a, b$, and $c$. Therefore, the loss is the greatest when $\lambda_{1}$ is somewhere between 0.5 and 1 , as shown in those figures. In addition, Figures 3(a) and 3(c) show that the revenue loss is increasing as $a, c$ get larger, but the loss becomes insignificant as $b$ gets larger.

Secondly, we think about the more realistic assumption that the demands for each product are not identical. Thus, in this case, we vary the demand parameters of the core product (assume it is product 1), while keeping the parameters of the other products fixed.

Figures 4(a) and 4(b) show the effects of the magnitude of the demand and the magnitude of the sensitive demand $b$ of the core products on the loss of revenue, respectively. The results are no longer symmetric when $\lambda_{1}=0.5$. From Figure 4(a), we can easily see that if $a_{1}<a_{2}$, then the loss is the highest when product 1 is the core product and $\lambda_{1}>0.5$ and vice versa.

Figure 4(b) illustrates the effects of the price sensitivity of demand for the core product. With respect to $\lambda_{1}$, we find that if $b_{1}<b_{2}$, then the loss is the highest when $\lambda_{1}<0.5$ and vice versa.

\section{Conclusion}

On FT market, the changing of the consumer's preference to products because of the changing fashion trend is the major cause of demand variations. When retailer sells multiple fashion-like products, he could set a lower price for a small number of core products to lure more consumers to arrive at his store and then to increase the sales of other noncore products. He accordingly will earn more profits.

In this paper, we develop a multiproduct dynamic pricing model based on first-end reference-price updating formation in FT industry. And we analyze the optimal policy's characteristic for two and $N$ fashion-like products. Consistent with the literature, our results showed that the value of the steady-state prices decreases with consumers' sensitivity to gains and losses. In contrast with previous literature, we find that the length of consumers' memory window affects the range of optimal price and retailers' profit. Meanwhile, by 


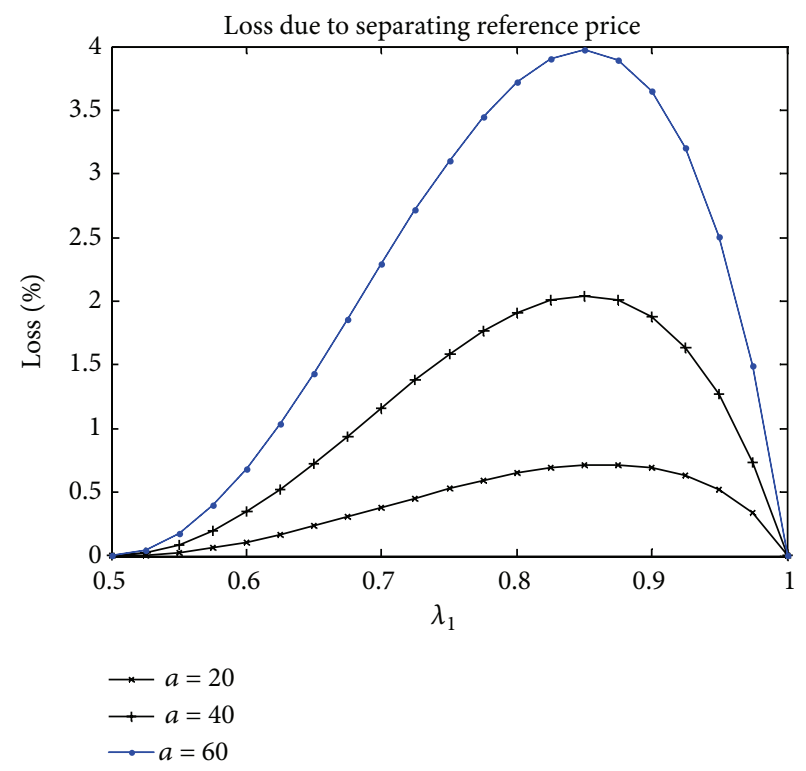

(a)

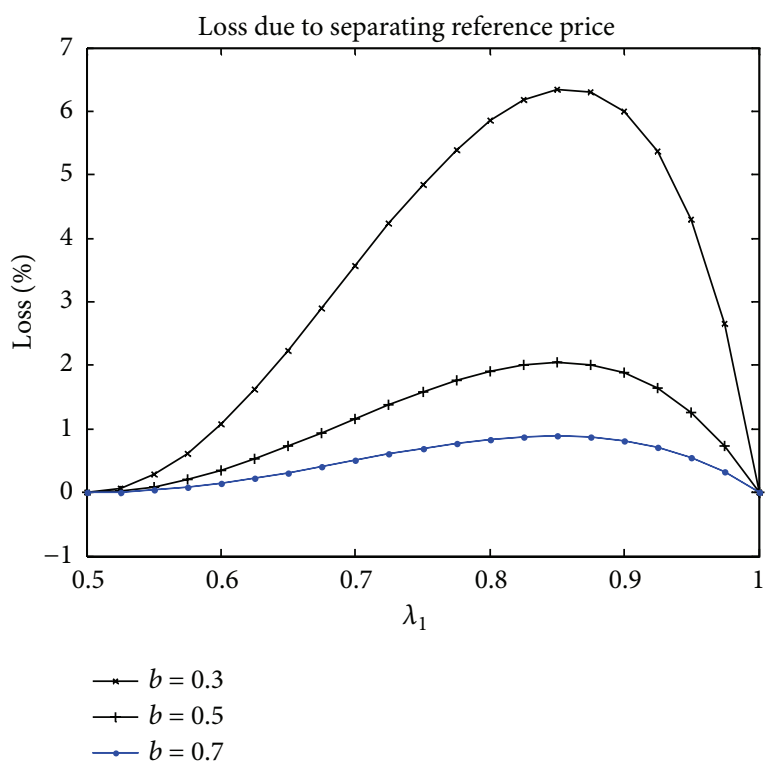

(b)

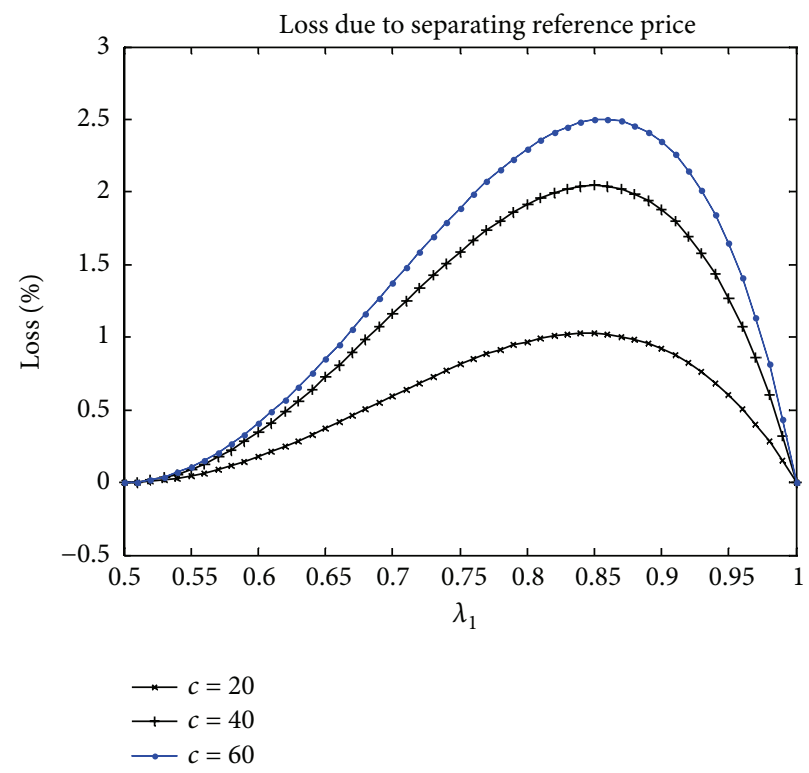

(c)

Figure 3: (a) Effects of magnitude of demand on revenue loss for identical products $\left(D_{1}\left(p_{1}, p_{2}, r\right)=40-0.5 p_{1}+20 * \lambda_{1}\left(r-\lambda_{1} p_{1}-\right.\right.$ $\left.\left.\lambda_{2} p_{2}\right), D_{2}\left(p_{1}, p_{2}, r\right)=40-0.5 p_{2}+20 * \lambda_{2}\left(r-\lambda_{1} p_{1}-\lambda_{2} p_{2}\right), r_{0}=10, \alpha=0.2, \gamma=0.95\right)$. (b) Effects of magnitude of demand on revenue loss for identical products $\left(D_{1}\left(p_{1}, p_{2}, r\right)=40-0.5 p_{1}+20 * \lambda_{1}\left(r-\lambda_{1} p_{1}-\lambda_{2} p_{2}\right), D_{2}\left(p_{1}, p_{2}, r\right)=40-0.5 p_{2}+20 * \lambda_{2}\left(r-\lambda_{1} p_{1}-\lambda_{2} p_{2}\right), r_{0}=\right.$ $10, \alpha=0.2, \gamma=0.95)$. (c) Effects of magnitude of demand on revenue loss for identical products $\left(D_{1}\left(p_{1}, p_{2}, r\right)=40-0.5 p_{1}+20 * \lambda_{1}(r-\right.$ $\left.\left.\lambda_{1} p_{1}-\lambda_{2} p_{2}\right), D_{2}\left(p_{1}, p_{2}, r\right)=40-0.5 p_{2}+20 * \lambda_{2}\left(r-\lambda_{1} p_{1}-\lambda_{2} p_{2}\right), r_{0}=10, \alpha=0.2, \gamma=0.95\right)$.

classifying the fashion products into core products and noncore products, we find that a retailer will increase its revenue if it chooses an optimal pricing strategy based on storelevel reference price instead of product level. Our results also suggested that customers' behavioral parameters such as length of memory window $\tau$ are important for a retailer to measure in order to determine its optimal pricing strategy. It influences the optimal price policy's steady state, speed of converge, and the retailer's long-term profit. So it is essential for a retailer to anticipate this parameter by marketing research and plan its pricing policy according to it. 


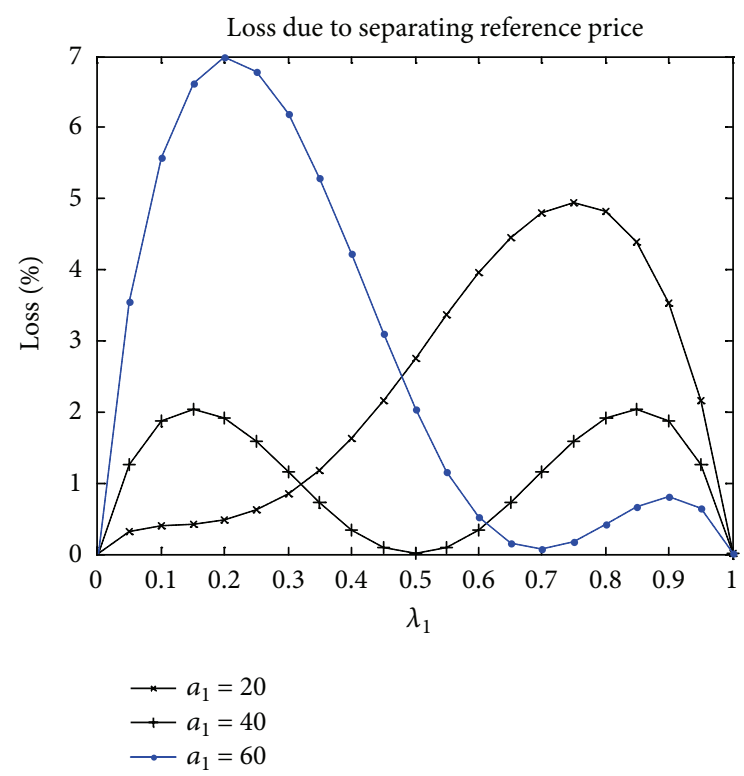

(a)

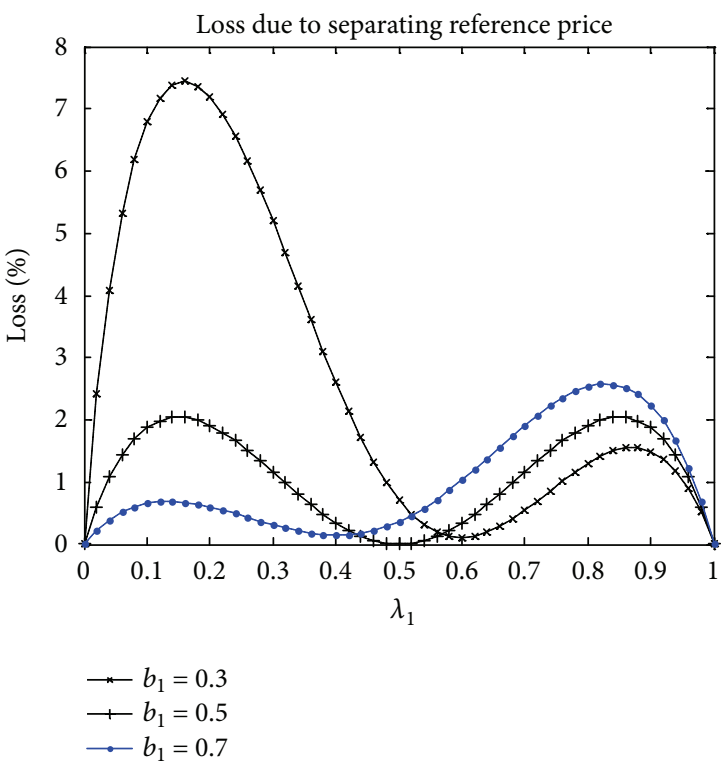

(b)

FIgURE 4: (a) Effects of magnitude of demand of the core products on revenue loss $\left(D_{1}\left(p_{1}, p_{2}, r\right)=a_{1}-0.5 p_{1}+20 * \lambda_{1}\left(r-\lambda_{1} p_{1}-\right.\right.$ $\left.\lambda_{2} p_{2}\right), D_{2}\left(p_{1}, p_{2}, r\right)=40-0.5 p_{2}+20 * \lambda_{2}\left(r-\lambda_{1} p_{1}-\lambda_{2} p_{2}\right), r_{0}=$ $10, \alpha=0.2, \gamma=0.95)$. (b) Effects of magnitude of demand of the core products on revenue loss $\left(D_{1}\left(p_{1}, p_{2}, r\right)=40-b_{1} p_{1}+20 *\right.$ $\lambda_{1}\left(r-\lambda_{1} p_{1}-\lambda_{2} p_{2}\right), D_{2}\left(p_{1}, p_{2}, r\right)=40-0.5 p_{2}+20 * \lambda_{2}\left(r-\lambda_{1} p_{1}-\right.$ $\left.\left.\lambda_{2} p_{2}\right), r_{0}=10, \alpha=0.2, \gamma=0.95\right)$.

For future work, we intend to extend the results to the setting, where customers learn to adjust their expectations strategically. In addition, empirical work is needed to better understand consumer behavior with regard to repeated purchase.

\section{Appendix}

Proof of Proposition 3. As the proof of Proposition 3, the Euler equilibrium conditions (Fackler and Mario Miranda [42]) for two products are

$$
\begin{gathered}
\prod_{\mathbf{p}^{t}}\left(\mathbf{s}^{t}, \mathbf{p}^{t}\right)+\gamma \boldsymbol{v} g_{\mathbf{p}^{t}}\left(\mathbf{s}^{t}, \mathbf{p}^{t}\right)=0, \\
\boldsymbol{v}=\prod_{\mathbf{s}^{t}}\left(\mathbf{s}^{t}, \mathbf{p}^{t}\right)+\gamma \boldsymbol{v} g_{\mathbf{s}^{t}}\left(\mathbf{s}^{t}, \mathbf{p}^{t}\right), \\
\mathbf{s}^{t+1}=g\left(\mathbf{s}^{t}, \mathbf{p}^{t}\right),
\end{gathered}
$$

where state vector

$$
\begin{gathered}
\mathbf{s}^{t}=\left(p_{1}^{t-\tau}, \ldots, p_{1}^{t-1}, p_{2}^{t-\tau}, \ldots, p_{2}^{t-1}\right), \\
\mathbf{s}^{t+1}=g\left(\mathbf{s}^{t}, \mathbf{p}^{t}\right)=\left(p_{1}^{t-\tau+1}, \ldots, p_{1}^{t}, p_{2}^{t-\tau+1}, \ldots, p_{2}^{t}\right),
\end{gathered}
$$

price vector $\mathbf{p}^{t}=\left[p_{1}^{t}, p_{2}^{t}\right]$, shadow price $\boldsymbol{v}=\left(v_{1}^{\tau}, \ldots\right.$, $\left.v_{1}^{1}, v_{2}^{\tau}, \ldots, v_{2}^{1}\right)$, the derivatives of $\prod\left(\mathbf{s}^{t}, \mathbf{p}^{t}\right)$ on $\mathbf{s}^{t}, \mathbf{p}^{t}$ are

$$
\begin{aligned}
\prod_{\mathbf{p}^{t}}\left(\mathbf{s}^{t}, \mathbf{p}^{t}\right)= & {\left[\frac{\partial \prod\left(\mathbf{s}^{t}, \mathbf{p}^{t}\right)}{\partial p_{1}^{t}}, \frac{\partial \prod\left(\mathbf{s}^{t}, \mathbf{p}^{t}\right)}{\partial p_{2}^{t}}\right], } \\
\prod_{\mathbf{p}^{t}}\left(\mathbf{s}^{t}, \mathbf{p}^{t}\right)=( & \frac{\partial \prod\left(\mathbf{s}^{t}, \mathbf{p}^{t}\right)}{\partial p_{1}^{t-\tau}}, \ldots, \frac{\partial \prod\left(\mathbf{s}^{t}, \mathbf{p}^{t}\right)}{\partial p_{1}^{t-1}}, \\
& \left.\frac{\partial \prod\left(\mathbf{s}^{t}, \mathbf{p}^{t}\right)}{\partial p_{2}^{t-\tau}}, \ldots, \frac{\partial \prod\left(\mathbf{s}^{t}, \mathbf{p}^{t}\right)}{\partial p_{2}^{t-1}}\right) .
\end{aligned}
$$

and the derivatives of $g\left(\mathbf{s}^{t}, \mathbf{p}^{t}\right)$ on $\mathbf{s}^{t}, \mathbf{p}^{t}$ are

$$
\begin{aligned}
g_{\mathbf{p}^{t}} & =\left[\begin{array}{l}
\frac{\partial p_{1}^{t-\tau+1}}{\partial p_{1}^{t}}, \ldots, \frac{\partial p_{1}^{t}}{\partial p_{1}^{t}}, \frac{\partial p_{2}^{t-\tau+1}}{\partial p_{1}^{t}}, \ldots, \frac{\partial p_{2}^{t}}{\partial p_{1}^{t}} \\
\frac{\partial p_{1}^{t \tau+1}}{\partial p_{2}^{t}}, \ldots, \frac{\partial p_{1}^{t}}{\partial p_{2}^{t}}, \frac{\partial p_{2}^{t-\tau+1}}{\partial p_{2}^{t}}, \ldots, \frac{\partial p_{2}^{t}}{\partial p_{2}^{t}}
\end{array}\right]^{\prime} \\
& =\left[\begin{array}{l}
0, \ldots, 1,0, \ldots, 0 \\
0, \ldots, 0,0, \ldots, 1
\end{array}\right]^{\prime},
\end{aligned}
$$

$$
g_{\mathbf{s}^{t}}=\left[\begin{array}{c}
\frac{\partial p_{1}^{t-\tau+1}}{\partial p_{1}^{t-\tau}}, \ldots, \frac{\partial p_{1}^{t}}{\partial p_{1}^{t-\tau}}, \frac{\partial p_{2}^{t-\tau+1}}{\partial p_{1}^{t-\tau}}, \ldots, \frac{\partial p_{2}^{t}}{\partial p_{1}^{t-\tau}} \\
\vdots \\
\frac{\partial p_{1}^{t-\tau+1}}{\partial p_{1}^{t-1}}, \ldots, \frac{\partial p_{1}^{t}}{\partial p_{1}^{t-1}}, \frac{\partial p_{2}^{t-\tau+1}}{\partial p_{1}^{t-1}}, \ldots, \frac{\partial p_{2}^{t}}{\partial p_{1}^{t-1}} \\
\frac{\partial p_{1}^{t-\tau+1}}{\partial p_{2}^{t-\tau}}, \ldots, \frac{\partial p_{1}^{t}}{\partial p_{2}^{t-\tau}}, \frac{\partial p_{2}^{t+\tau+1}}{\partial p_{2}^{t-\tau}}, \ldots, \frac{\partial p_{2}^{t}}{\partial p_{2}^{t-\tau}} \\
\vdots \\
\frac{\partial p_{1}^{t-\tau+1}}{\partial p_{2}^{t-1}}, \ldots, \frac{\partial p_{1}^{t}}{\partial p_{2}^{t-1}}, \frac{\partial p_{2}^{t-\tau+1}}{\partial p_{2}^{t-1}}, \ldots, \frac{\partial p_{2}^{t}}{\partial p_{2}^{t-1}}
\end{array}\right]
$$

$$
=\left[\begin{array}{cc|cc}
\mathbf{0} & \mathbf{I}_{(\tau-1) \times(\tau-1)} & \mathbf{0} & \mathbf{0}_{(\tau-1) \times(\tau-1)} \\
0 & \mathbf{0} & 0 & \mathbf{0} \\
\hline \mathbf{0} & \mathbf{0}_{(\tau-1) \times(\tau-1)} & \mathbf{0} & \mathbf{I}_{(\tau-1) \times(\tau-1)} \\
0 & \mathbf{0} & 0 & \mathbf{0}
\end{array}\right]_{2 \tau \times 2 \tau}
$$

$\left(\mathbf{I}_{(\tau-1) \times(\tau-1)}\right.$ is a unit matrix). 
So we can rewrite (A.1) as the following equations:

$$
\begin{aligned}
& \frac{\partial \prod\left(s_{t}, p_{t}\right)}{\partial p_{1}^{t}}+\gamma\left(\frac{\partial \prod\left(s_{t}, p_{t}\right)}{\partial p_{1}^{t-1}}+\gamma^{\tau-1} \frac{\partial \prod\left(s_{t}, p_{t}\right)}{\partial p_{1}^{t-\tau}}\right)=0 \\
& \frac{\partial \prod\left(s_{t}, p_{t}\right)}{\partial p_{2}^{t}}+\gamma\left(\frac{\partial \prod\left(s_{t}, p_{t}\right)}{\partial p_{2}^{t-1}}+\gamma^{\tau-1} \frac{\partial \prod\left(s_{t}, p_{t}\right)}{\partial p_{2}^{t-\tau}}\right)=0 .
\end{aligned}
$$

According to Assumption 1, the profits of two products are

$$
\begin{aligned}
& \prod\left(\mathbf{s}^{t}, \mathbf{p}^{t}\right)= D_{1}\left(r^{t}, \mathbf{p}^{t}\right) p_{1}^{t}+D_{2}\left(r^{t}, \mathbf{p}^{t}\right) p_{2}^{t} \\
&=\left(a_{1}-b_{1} p_{1}^{t}+c^{G} \lambda_{1}\left(r_{t}-\lambda_{1} p_{1}^{t}-\lambda_{2} p_{2}^{t}\right)\right) p_{1}^{t} \\
&+\left(a_{2}-b_{2} p_{2}^{t}+c^{G} \lambda_{2}\left(r_{t}-\lambda_{1} p_{1}^{t}-\lambda_{2} p_{2}^{t}\right)\right) p_{2}^{t}, \\
& r^{t}=\alpha\left(\lambda_{1} p_{1}^{t-\tau}+\lambda_{2} p_{2}^{t-\tau}\right)+(1-\alpha)\left(\lambda_{1} p_{1}^{t-1}+\lambda_{2} p_{2}^{t-1}\right) .
\end{aligned}
$$

So we have

$$
\begin{aligned}
& \frac{\partial \prod\left(\mathbf{s}^{t}, \mathbf{p}^{t}\right)}{\partial p_{1}^{t}}=a_{1}-b_{1} p_{1}^{t}+c^{G} \lambda_{1}\left(r^{t}-\lambda_{1} p_{1}^{t}-\lambda_{2} p_{2}^{t}\right) \\
& +\left(-b_{1}-c^{G} \lambda_{1} \lambda_{1}\right) p_{1}^{t}-c^{G} \lambda_{2} \lambda_{1} p_{2}^{t}, \\
& \frac{\partial \prod\left(\mathbf{s}^{t}, \mathbf{p}^{t}\right)}{\partial p_{2}^{t}}=a_{2}-b_{2} p_{2}^{t}+c^{G} \lambda_{2}\left(r-\lambda_{1} p_{1}^{t}-\lambda_{2} p_{2}^{t}\right) \\
& +\left(-b_{2}-c^{G} \lambda_{2} \lambda_{2}\right) p_{2}^{t}-c^{G} \lambda_{1} \lambda_{2} p_{1}^{t}, \\
& \frac{\partial \prod\left(\mathbf{s}^{t}, \mathbf{p}^{t}\right)}{\partial p_{1}^{t-\tau}}=c^{G} \lambda_{1} \alpha \lambda_{1} p_{1}^{t}+c^{G} \lambda_{2} \alpha \lambda_{1} p_{2}^{t}, \\
& \frac{\partial \prod\left(\mathbf{s}^{t}, \mathbf{p}^{t}\right)}{\partial p_{1}^{t-1}}=c^{G} \lambda_{1}(1-\alpha) \lambda_{1} p_{1}^{t}+c^{G} \lambda_{2}(1-\alpha) \lambda_{1} p_{2}^{t}, \\
& \frac{\partial \prod\left(\mathbf{s}^{t}, \mathbf{p}^{t}\right)}{\partial p_{2}^{t-\tau}}=c^{G} \lambda_{1} \alpha \lambda_{2} p_{1}^{t}+c^{G} \lambda_{2} \alpha \lambda_{2} p_{2}^{t}, \\
& \frac{\partial \prod\left(\mathbf{s}^{t}, \mathbf{p}^{t}\right)}{\partial p_{2}^{t-1}}=c^{G} \lambda_{1}(1-\alpha) \lambda_{2} p_{1}^{t}+c^{G} \lambda_{2}(1-\alpha) \lambda_{2} p_{2}^{t} \text {. }
\end{aligned}
$$

In steady state, $p_{1}^{t-\tau}=\cdots=p_{1}^{t-1}=p_{1}^{L^{*}}, p_{2}^{t-\tau}=\cdots=p_{2}^{t-1}=$ $p_{2}^{L^{*}}$; by substituting above partial derivatives of $\prod\left(\mathbf{s}^{t}, \mathbf{p}^{t}\right)$ on $\mathrm{s}^{t}, \mathrm{p}^{t}$ into (A.5), we get

$$
\begin{aligned}
& k_{11} p_{1}^{L^{*}}+k_{12} p_{2}^{L^{*}}=a_{1}, \\
& k_{21} p_{1}^{L^{*}}+k_{22} p_{2}^{L^{*}}=a_{2},
\end{aligned}
$$

where

$$
\begin{aligned}
& k_{11}=\left(-2 b_{1}+c^{G} \lambda_{1}^{2}\left(\gamma\left(1-\alpha\left(1-\gamma^{\tau-1}\right)\right)-1\right)\right), \\
& k_{12}=k_{21}=\left(c^{G} \lambda_{1} \lambda_{2}\left(\gamma\left(1-\alpha\left(1-\gamma^{\tau-1}\right)\right)-1\right)\right), \\
& k_{22}=\left(-2 b_{2}+c^{G} \lambda_{2}^{2}\left(\gamma\left(1-\alpha\left(1-\gamma^{\tau-1}\right)\right)-1\right)\right) .
\end{aligned}
$$

So we have

$$
p_{1}^{L^{*}}=\frac{a_{1} k_{22}-a_{2} k_{12}}{k_{11} k_{22}-k_{12} k_{21}}, \quad p_{2}^{L^{*}}=\frac{a_{2} k_{11}-a_{1} k_{21}}{k_{11} k_{12}-k_{12} k_{21}} .
$$

\section{Notations}

$T(T \geq 1):$ $t(T \geq t \geq 1)$ : $D_{j}\left(D_{j} \geq 0\right)$ : $\quad$ Unit(s) demand of product $j$ Length of the planning horizon $p_{j}^{t}\left(\bar{p} \geq p_{t}>\underline{p}\right)$ : Per unit sales price in period $t$ of product $j$

$r^{t}\left(\bar{r} \geq r^{t}>\underline{r}\right)$ : $\quad$ Per unit reference price in period $t$ $\gamma(1 \geq \gamma>0)$ : Discount factor $\alpha(1>\alpha \geq 0)$ :

Memory parameter (captures how strongly the reference price depends on past prices)

$\tau(\tau>0)$ Length of consumer's memory window

$\alpha_{j}\left(\alpha_{j}>0\right)$ $b_{j}\left(b_{j}>0\right)$ : The maximum demand of product $j$ Coefficient the price-demand sensitivity of product $j$

$c_{G}\left(c_{G}>0\right)$ Coefficient of reference effect when

$c_{L}\left(c_{L}>0\right)$ : $p_{t}>r_{t}$ Coefficient of reference effect when $p_{t} \leq r_{t}$

$V_{t}(x): \quad$ Expected optimal profit-to-go $p_{1}^{L^{*}}: \quad$ The optimal price path of product 1 $p_{2}^{L^{*}}: \quad$ The optimal price path of product 2 $\lambda_{j}(0<\lambda<1)$ : The proportion of product $j$ when calculating the price level.

\section{Conflict of Interests}

The authors declare that there is no conflict of interests regarding the publication of this paper.

\section{Acknowledgment}

This research is supported by the National Natural Science Foundation of China (Grant nos. 71371191, 70971139, 71221061, and 71210003).

\section{References}

[1] Y. Aviv and A. Pazgal, Dynamic Pricing of Short Life-Cycle Products Through Active Learning, Olin School Business, Washington University, St. Louis, Mo, USA, 2005.

[2] P. Ghemawat, J. L. Nueno, and M. Dailey, Zara: Fast Fashion, Harvard Business School, 2003.

[3] M. Baucells, M. Weber, and F. Welfens, "Reference-point formation and updating," Management Science, vol. 57, no. 3, pp. 506-519, 2011.

[4] R. Sarin, "Decision rules with bounded memory," Journal of Economic Theory, vol. 90, no. 1, pp. 151-160, 2000.

[5] G. R. Bitran and S. V. Mondschein, "Periodic pricing of seasonal products in retailing," Management Science, vol. 43, no. 1, pp. 64-79, 1997. 
[6] E. P. Lazear, "Salaries and piece rates," The Journal of Business, vol. 59, no. 3, pp. 405-431, 1986.

[7] Y. Aviv, G. Vulcano, Ö. Özer, and R. Phillips, "Dynamic list pricing," in The Oxford Handbook of Pricing Management, pp. 522-584, Oxford University Press, Oxford, UK, 2012.

[8] W. Zhao and Y.-S. Zheng, "Optimal dynamic pricing for perishable assets with nonhomogeneous demand," Management Science, vol. 46, no. 3, pp. 375-388, 2000.

[9] S. Bhattacharjee and R. Ramesh, "Multi-period profit maximizing model for retail supply chain management: an integration of demand and supply-side mechanisms," European Journal of Operational Research, vol. 122, no. 3, pp. 584-601, 2000.

[10] G. R. Bitran and S. V. Mondschein, "Periodic pricing of seasonal products in retailing," Management Science, vol. 43, no. 1, pp. 64-79, 1997.

[11] C. H. Loch, Behavioral Operations Management, Now Publishers, 2007.

[12] F. Gino and G. Pisano, "Toward a theory of behavioral operations," Manufacturing \& Service Operations Management, vol. 10, no. 4, pp. 676-691, 2008.

[13] Z.-J. M. Shen and X. Su, "Customer behavior modeling in revenue management and auctions: a review and new research opportunities," Production and Operations Management, vol. 16, no. 6, pp. 713-728, 2007.

[14] V. Gaur and Y. H. Park, "Asymmetric consumer learning and inventory competition," Management Science, vol. 53, no. 2, pp. 227-240, 2007.

[15] Q. Liu and G. J. van Ryzin, "Strategic capacity rationing to induce early purchases," Management Science, vol. 54, no. 6, pp. 1115-1131, 2008.

[16] A. Ovchinnikov and J. M. Milner, "Revenue management with end-of-period discounts in the presence of customer learning," Production and Operations Management, vol. 21, no. 1, pp. 6984, 2012.

[17] M. Natter, T. Reutterer, A. Mild, and A. Taudes, "Practice prize report-an assortmentwide decision-support system for dynamic pricing and promotion planning in DIY retailing," Marketing Science, vol. 26, no. 4, pp. 576-583, 2007.

[18] G. Fibich, A. Gavious, and O. Lowengart, "Explicit solutions of optimization models and differential games with nonsmooth (asymmetric) reference-price effects," Operations Research, vol. 51, no. 5, pp. 721-734, 2003.

[19] P. Heidhues and B. Koszegi, "The impact of consumer loss aversion on pricing," Markets and Political Economy Working Paper SP II, WZB, 2004.

[20] I. Popescu and Y. Wu, "Dynamic pricing strategies with reference effects," Operations Research, vol. 55, no. 3, pp. 413-429, 2007.

[21] W. T. Huh, S. Kachani, and A. Sadighian, "A two-stage multiperiod negotiation model with reference price effect," Journal of Revenue \& Pricing Management, vol. 9, no. 5, pp. 443-475, 2010.

[22] H. Arslan and S. Kachani, "Dynamic pricing under consumer reference-price effects," in Wiley Encyclopedia of Operations Research and Management Science, 2011.

[23] E. A. Greenleaf, "The impact of reference price effects on the profitability of price promotions," Marketing Science, vol. 14, no. 1, pp. 82-104, 1995.

[24] S. L. Puller and J. West, "Efficient retail pricing in electricity and natural gas markets," American Economic Review, vol. 103, no. 3, pp. 350-355, 2013.
[25] T. H. Ho, N. Lim, and C. F. Camerer, "Modeling the psychology of consumer and firm behavior with behavioral economics," Journal of Marketing Research, vol. 43, no. 3, pp. 307-331, 2006.

[26] T. Yucek and H. Arslan, "A survey of spectrum sensing algorithms for cognitive radio applications," IEEE Communications Surveys \& Tutorials, vol. 11, no. 1, pp. 116-130, 2009.

[27] P. K. Kopalle, A. G. Rao, and J. L. Assuncao, "Asymmetric reference price effects and dynamic pricing policies," Marketing Science, vol. 15, no. 1, pp. 60-85, 1996.

[28] D. Huh, B. D. Matthews, A. Mammoto, M. Montoya-Zavala, H. Y. Hsin, and D. E. Ingber, "Reconstituting organ-level lung functions on a chip," Science, vol. 328, no. 5986, pp. 1662-1668, 2010.

[29] J. Nasiry and I. Popescu, "Dynamic pricing with loss-averse consumers and peak-end anchoring," Operations Research, vol. 59, no. 6, pp. 1361-1368, 2011.

[30] B. L. Fredrickson and D. Kahneman, "Duration neglect in retrospective evaluations of affective episodes," Journal of Personality and Social Psychology, vol. 65, no. 1, pp. 45-55, 1993.

[31] T. Mazumdar, S. Raj, and I. Sinha, "Reference price research: review and propositions," Journal of Marketing, vol. 69, no. 4, pp. 84-102, 2005.

[32] D. Kahneman, "Evaluation by moments: past and future," in Choices, Values, and Frames, D. Kahneman and A. Tversky, Eds., pp. 693-708, 2000.

[33] M. Do, A. V. Rupert, and G. Wolford, "Evaluations of pleasurable experiences: the peak-end rule," Psychonomic Bulletin \& Review, vol. 15, no. 1, pp. 96-98, 2008.

[34] R. J. Aumann and S. Sorin, "Cooperation and bounded recall," Games and Economic Behavior, vol. 1, no. 1, pp. 5-39, 1989.

[35] G. Gallego and G. van Ryzin, "Optimal dynamic pricing of inventories with stochastic demand over finite horizons," Management Science, vol. 40, no. 8, pp. 999-1020, 1994.

[36] C. Maglaras and J. Meissner, "Dynamic pricing strategies for multiproduct revenue management problems," Manufacturing \& Service Operations Management, vol. 8, no. 2, pp. 136-148, 2006.

[37] A. Asvanunt and S. Kachani, "Multi-product pricing with reference effects in monopoly and duopoly markets," Working Paper, Columbia University, 2008.

[38] N. Calicchio and A. Krell, Price Promotions in Latin American Retailing, McKinsey Quarterly Review, 2007.

[39] L. Krishnamurthi, T. Mazumdar, and S. Raj, "Asymmetric response to price in consumer brand choice and purchase quantity decisions," Journal of Consumer Research, vol. 19, no. 3, pp. 387-400, 1992.

[40] R. S. Winer, "A reference price model of brand choice for frequently purchased products," Journal of Consumer Research, vol. 13, pp. 250-256, 1986.

[41] J. E. Smith and K. F. Mccardle, "Structural properties of stochastic dynamic programs," Operations Research, vol. 50, no. 5, pp. 796-809, 2002.

[42] P. L. Fackler and J. Mario Miranda, Applied Computational Economics and Finance, The MIT Press, 2002. 


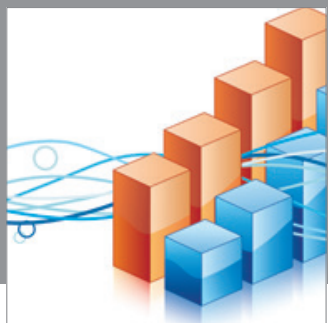

Advances in

Operations Research

mansans

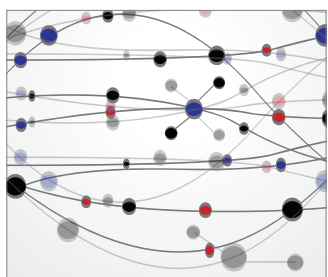

The Scientific World Journal
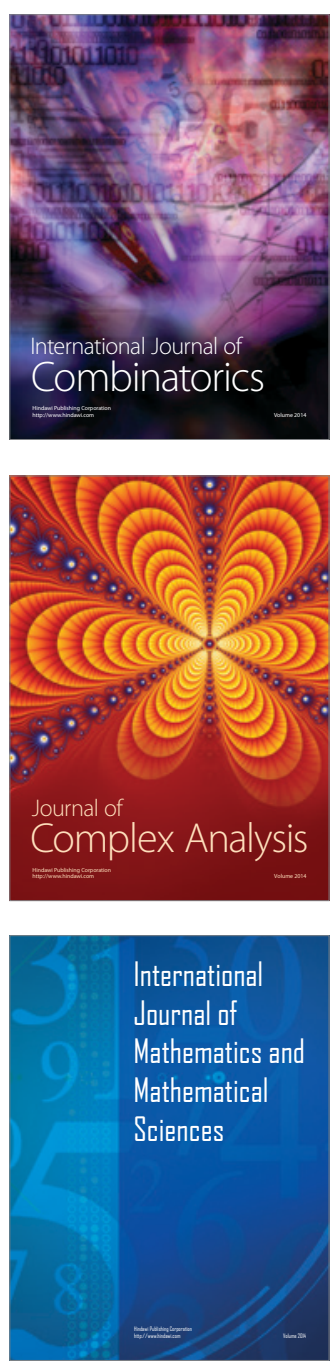
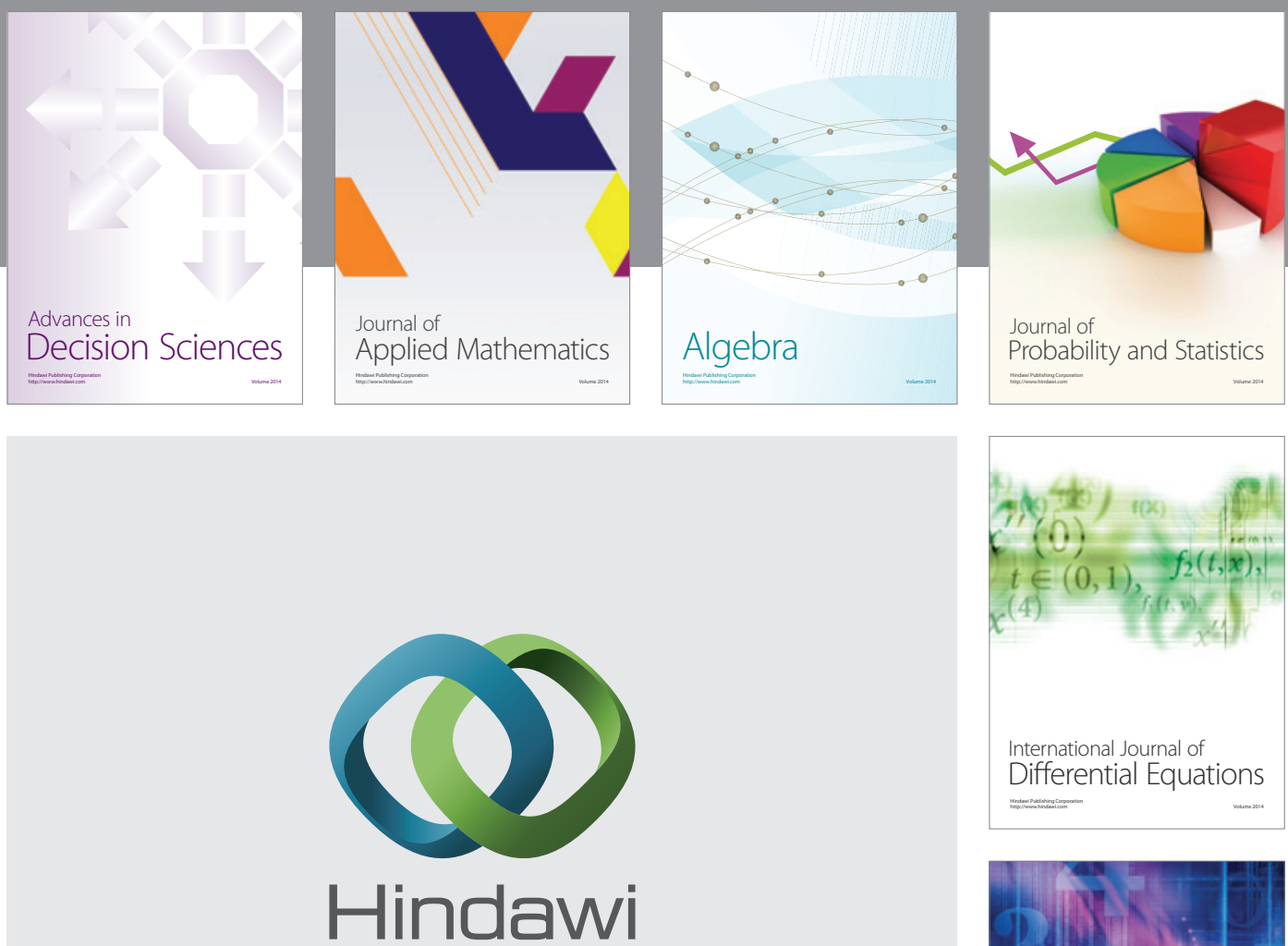

Submit your manuscripts at http://www.hindawi.com
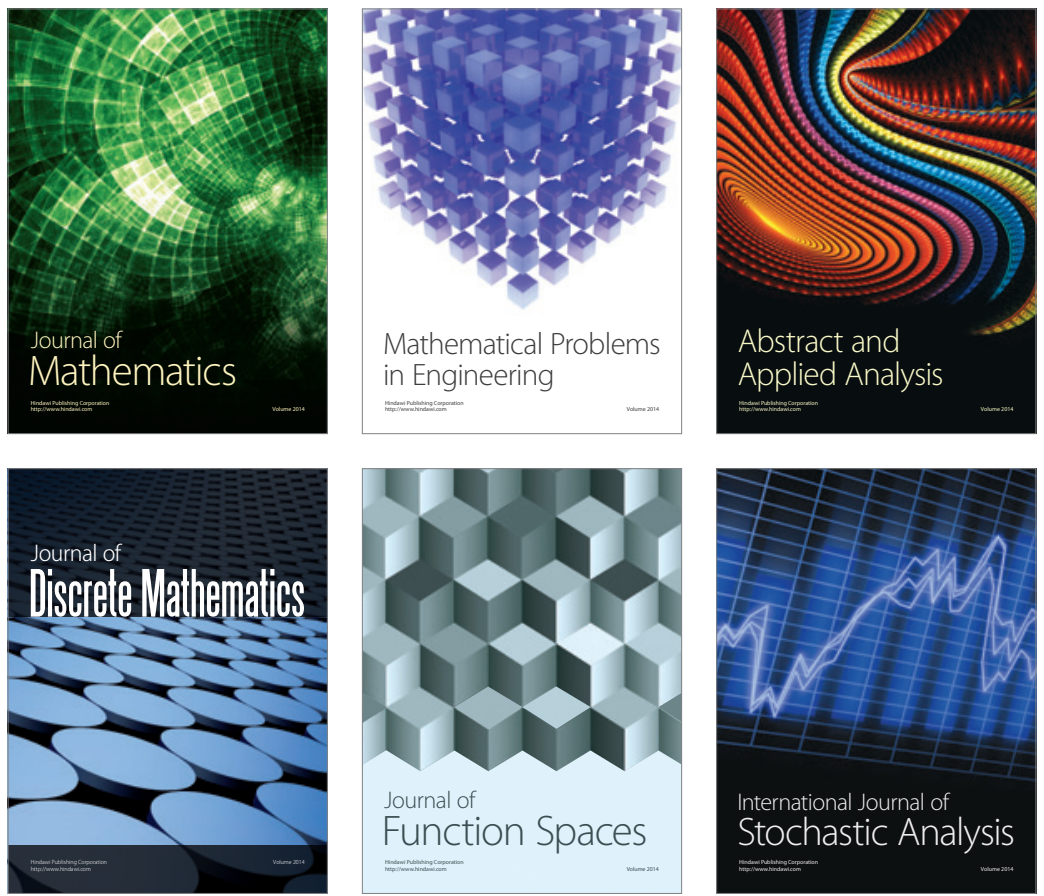

Journal of

Function Spaces

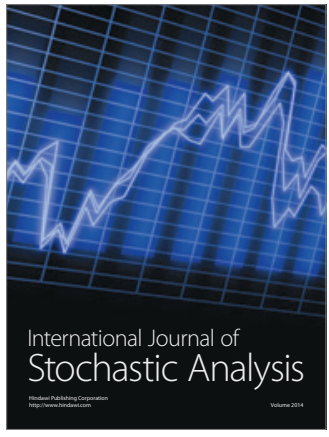

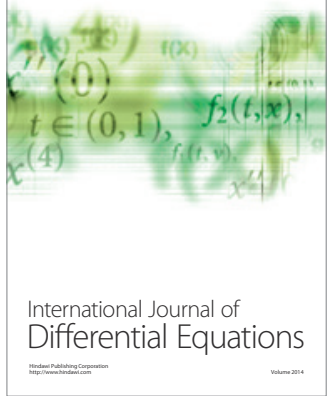
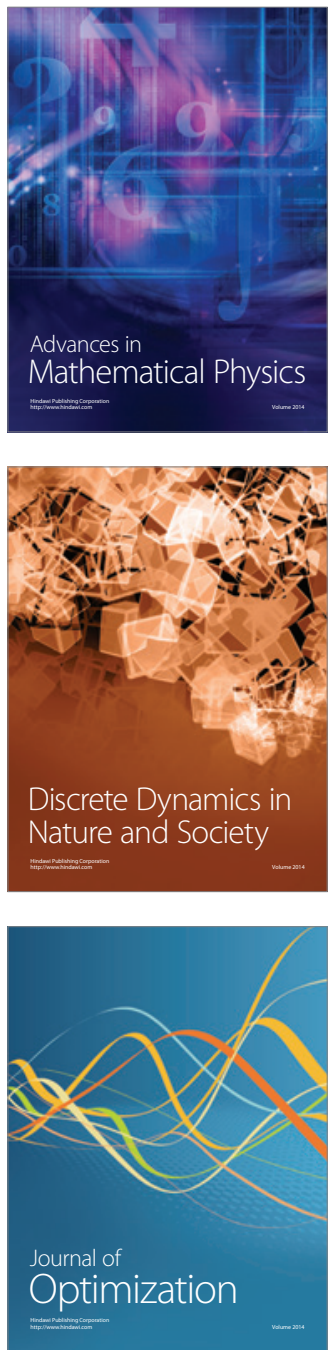